\title{
ESCRITA, MEMÓRIA E PAISAGEM
}

Ana Costa Ribeiro é artista e cineasta. Doutoranda em Arte e Cultura Contemporânea pela UERJ, possui Master of Fine Arts em Cinema pela San Francisco State University e graduação em Comunicação Social pela UFRJ. Seus trabalhos foram exibidos em festivais no Brasil, na Holanda, na Alemanha, na Espanha, na Índia e nos Estados Unidos. Atualmente desenvolve escrita e prática artística relacionadas ao projeto de pesquisa Poéticas do Deslocamento: Corpo, Memória, Paisagem. É professora de Narrativas Audiovisuais no Ateliê da Imagem. E-mail: costaribeiroana@gmail.com

\begin{abstract}
Resumo
$\mathrm{O}$ ensaio estabelece relações entre memória e paisagem através de diálogos com trabalhos dos artistas Tony Smith e Richard Long e dos cineastas Chris Marker e Maya Deren. O texto aborda a noção de escrita como atos de inscrição da passagem dos corpos no espaço e no tempo, por meio de atravessamentos da paisagem e de alinhamentos da memória.
\end{abstract}

\begin{abstract}
The essay establishes relations between memory and landscape through dialogs with works by artists Tony Smith and Richard Long and filmmakers Chris Marker and Maya Deren. The text addresses the notion of the written as acts of inscription of the passage of the bodies in space and time, by means of the crossings of landscape and the alignments of memory.
\end{abstract}

Por muito tempo achei que a ausência é falta.

E lastimava, ignorante, a falta.

Hoje não a lastimo.

Não há falta na ausência.

A ausência é um estar em mim.

E sinto-a, branca, tão pegada, aconchegada nos meus braços, que rio e danço e invento exclamações alegres, porque a ausência, essa ausência assimilada, ninguém a rouba mais de mim.

Carlos Drummond de Andrade Corpo

Sou um guardador de rebanhos. $O$ rebanho é os meus pensamentos E os meus pensamentos são todos sensações. Penso com os olhos e com os ouvidos E com as mãos e os pés E com o nariz e a boca.

Alberto Caeiro O Guardador de Rebanhos

“O vestígio é a inserção do espaço no tempo" (LÉVINAS, 2012, p. 65). Segundo o filósofo Emmanuel Lévinas, o vestígio inscreve temporalidade no espaço, uma vez que revela a presença de algo que já não está lá. O vestígio é a presença da ausência e a ausência, um estado que incorpora uma presença. De acordo com o pensamento de Lévinas, o vestígio instaura um silêncio - "resistência e atenção extrema do poeta e do artista: é, no sentido próprio do termo, guardar o silêncio. O poema ou a obra de arte guarda o silêncio, deixa ser a essência do ser, como o pastor guarda o seu rebanho" (LÉVINAS, 2012, p. 96). 


\section{1) Memória/ paisagem ou paisagem/ memória}

É preciso investigar de que forma lidamos tanto com a memória das paisagens que percorremos, quanto com as paisagens que percorremos em nossa memória. E se, através de atos de escrita, é possível avançar em direção a novas paisagens. Sabemos que as relações entre memória e paisagem se dão em inúmeras instâncias. Nesse sentido, será que falar da memória na paisagem é o mesmo que falar da paisagem na memória?

Antes de avançar, é importante apontar algumas noções de memória e paisagem que impulsionaram a escrita desse ensaio. Sobre a noção de memória, iniciamos com o verso de Waly Salomão: "a memória é uma ilha de edição" (SALOMÃO, 2014, p. 272, 273). Sobre a noção de paisagem, partimos do pensamento do filósofo Gilles A. Tiberghien: "há uma dimensão da paisagem que é fundamental, a de que ela é uma relação, e não uma coisa” (TIBERGHIEN, 2012, p. 180).

Acerca da relação entre memória e paisagem, o escritor Simon Schama já indica uma relação intrínseca entre esses conceitos, "conquanto estejamos habituados a situar a natureza e a percepção humana em dois campos distintos, na verdade elas são inseparáveis. Antes de poder ser um repouso para os sentidos, a paisagem é obra da mente. Compõe-se tanto de camadas de lembranças quanto de estratos de rochas" (SCHAMA, 1995, p. 17).

\section{2) Memória/paisagem}

A fim de desenvolver um pensamento sobre a memória na paisagem, vamos mencionar o trabalho de dois artistas que lidam com a questão da paisagem: o norteamericano Tony Smith e o inglês Richard Long. Ambos lidam com a paisagem num sentido que nos interessa, uma vez que consideram a questão do atravessamento. Ou seja, a paisagem como algo a ser atravessado ou como algo que tenha sido atravessado.

\section{1) Movimento de avanço e deslizamento em Tony Smith}

O relato de viagem de Tony Smith por uma estrada, publicado na revista Artforum em 1966, por exemplo, é emblemático nesse sentido.

Quando eu ensinava na Cooper Union, no começo dos anos cinquenta, alguém me informou como se fazia para entrar na New Jersey Turnpike, que ainda não tinha sido terminada. Peguei três estudantes e dirigi de um determinado ponto de Meadows até New Brunskwick. Era uma noite escura e não havia iluminação, nem sinalização no chão, nem as linhas do pavimento, nem muretas. Nada havia fora da estrada escura que corria por uma paisagem de planícies, circundada ao longe por colinas e pontilhada por chaminés, fábricas, torres, rios e luzes coloridas. Esse trajeto de carro foi uma revelação para mim. A estrada constituía uma grande parte da paisagem artificial; mas não se podia qualificá-la como obra de arte. Por outro lado, essa viagem fez por mim algo que a arte jamais fizera." (CARERI, 2013, p. 115). 


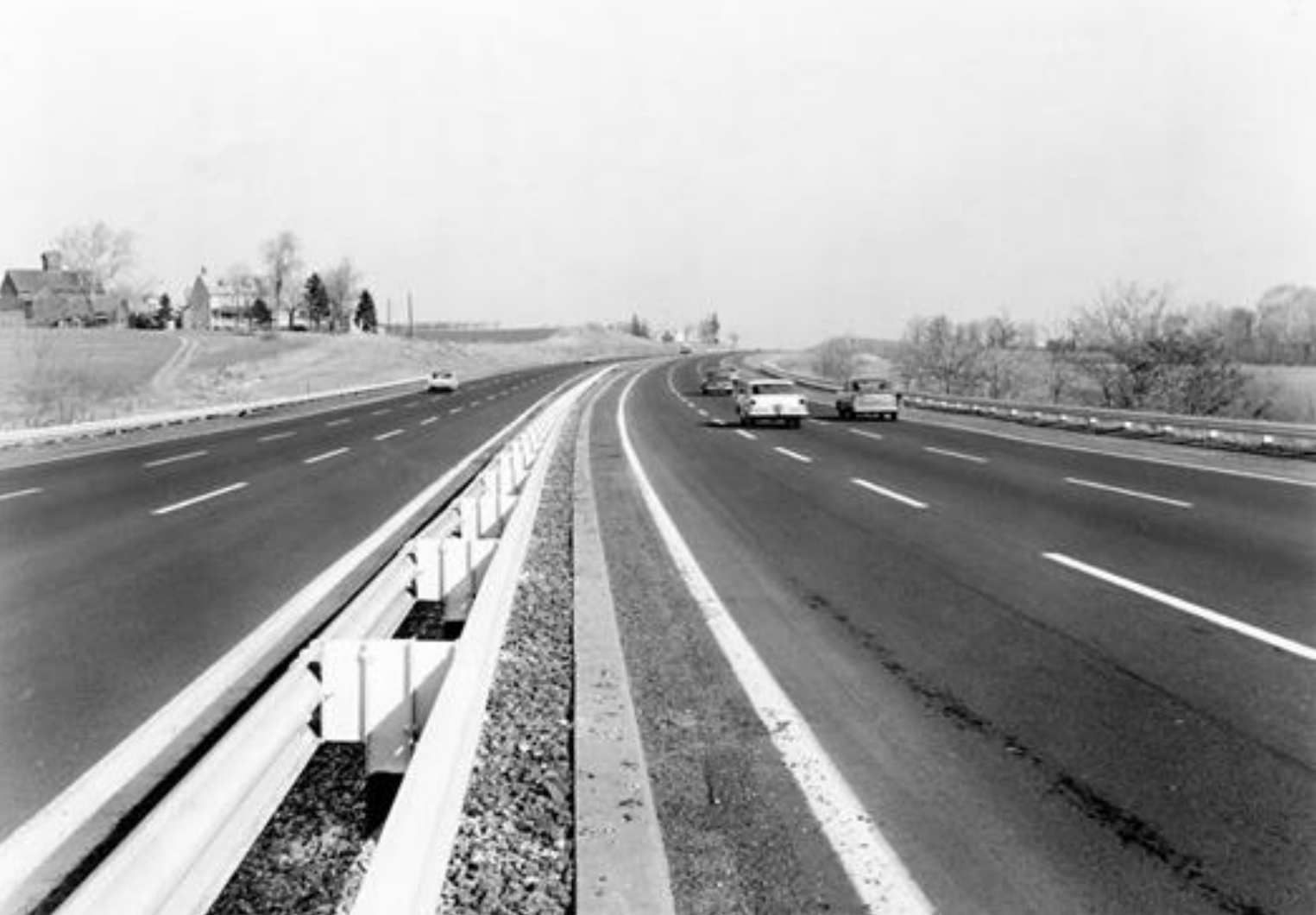

New Jersey Trunpike, Tony Smith, 1950s

Observando esse trabalho, já não podemos falar mais de uma paisagem bidimensional a ser contemplada, mas da relação do artista com a paisagem, a ser atravessada. É a experiência do artista com a travessia que irá relacionar a memória com a paisagem. Nesse caso, a memória da paisagem foi inscrita através do relato do artista. $\mathrm{O}$ vestígio se configura, portanto, no próprio relato, na inscrição da memória através da escrita.

\section{2) Movimento de fricção e atrito em Richard Long}

Sob influência do trabalho de Tony Smith, muitos artistas do final dos anos 60, e até hoje, têm lidado com essa problemática. Segundo Francesco Careri no livro Walkscapes, Richard Long vai além: "para ele, a arte consiste no ato mesmo de caminhar, na realização da sua experiência.” (CARERI, 2013, p. 113) 


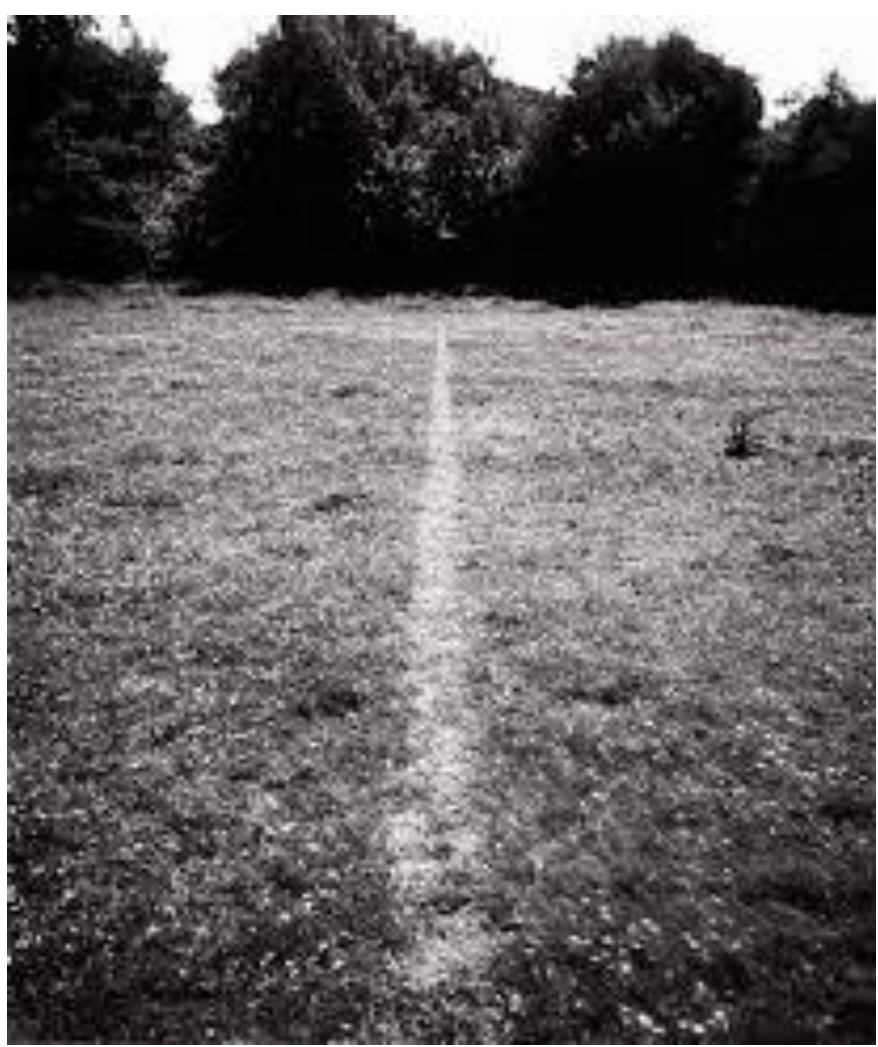

A Line Made by Walking, Richard Long, 1967

No trabalho de Long, há uma relação entre memória e paisagem que se aproxima particularmente de nossa abordagem: a passagem do artista pela paisagem deixa um rastro da ação de seu corpo. Esse vestígio, como diria Lévinas, insere o espaço no tempo. O corpo não está mais ali, mas sua ausência está. "A imagem da grama pisoteada contém em si a presença da ausência: ausência da ação, ausência do corpo, ausência do objeto. Mas, por outro lado, é inequivocamente o resultado da ação de um corpo". (CARERI, 2013, p. 125). Nesse sentido, a experiência cria uma relação entre memória e paisagem, uma vez que o deslocamento marca a ação de um corpo que já não está lá. O vestígio é a linha que se fez na grama através da caminhada do artista, como o próprio nome da obra indica.

\section{3) Paisagem/memória}

Pensemos agora no inverso: não mais na memória "da" ou "na" paisagem, e sim na paisagem "da" ou "na" memória. Pensar nas paisagens que aparecem em nossas memórias implica em pensar nas relações que temos com elas. Para tal, vamos analisar alguns aspectos de filmes de dois cineastas que lidam com a questão da memória: a ucraniana Maya Deren e o francês Chris Marker. Ambos lidam com a memória num sentido que nos interessa, uma vez que consideram a questão do alinhamento. Ou seja, a memória como algo a ser alinhado ou como algo que tenha sido alinhado. 


\section{1) Paisagem elástica e camadas de espaço em Chris Marker}

As relações entre paisagem e memória transpassam os limites do inconsciente. Há uma sequência em Sans Soleil (1983), de Chris Marker, em que o cineasta mostra japoneses dormindo num vagão de trem. Através de uma montagem repleta de inserts, Marker sugere que aqueles japoneses estão sonhando. Assim, não exclui o sonho da realidade uma vez que constrói uma paisagem elástica através de camadas de espaço.

É claro que as imagens e sons que Marker utiliza nessa sequência não correspondem ao que aquelas pessoas estavam sonhando. Mas ao inserir conteúdos de filmes japoneses, da TV japonesa e do Japão na sequência de japoneses dormindo no vagão de trem, o cineasta cria uma paisagem possível para os sonhos daquelas pessoas.

A sequência do filme de Marker coloca a questão sobre os limites entre consciente e inconsciente nas relações entre paisagens reais e imaginárias. Perceber o quanto a paisagem em que se vive interfere nos sonhos, lembranças, memórias, é algo que abre caminho para a criação de novas paisagens.

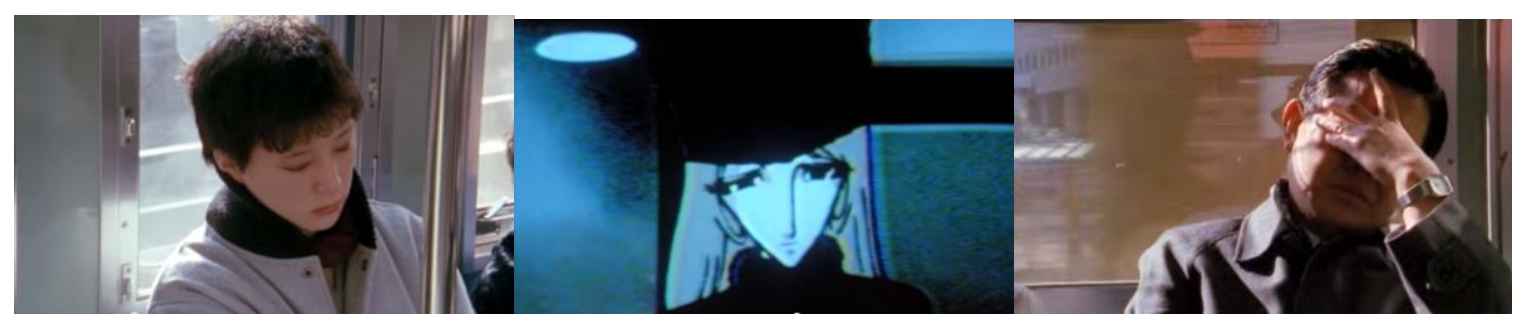

Sans Soleil, Chris Marker, 1983

Num determinado trecho do filme de Marker, a voz em off diz assim: "Eu poderia passar minha vida inteira tentando entender a função do ato de lembrar, que não é o oposto de esquecer, mas antes é alinhar". Alinhar o que se lembra é organizar fragmentos da memória em função de uma escrita. Uma escrita em diálogo com a memória deve incluir as paisagens do inconsciente, uma vez que nele também estão inscritos aspectos das paisagens pelas quais se percorre, tanto as reais quanto as imaginárias.

Como nos sonhos dos japoneses na sequência do filme de Marker, aquele que sonha cria novas paisagens a partir de paisagens conhecidas. Nesse sentido, as paisagens que surgem nos sonhos de um japonês serão sempre distintas das surgidas nos sonhos de um brasileiro, ou de um indiano, ou de um alemão. Torna-se imprescindível perceber de que forma o inconsciente faz deslocamentos criando novas paisagens a partir das paisagens comuns. Misturar paisagens reais e imaginárias é algo que nos coloca num posicionamento de suspensão entre os locais que percorremos através do consciente e do inconsciente. 


\section{2) Paisagem elástica e camadas de tempo em Maya Deren}

$\mathrm{Na}$ tradição do cinema moderno, onde a fusão entre realidade e imaginação é uma constante, podemos destacar o pensamento e a prática de uma cineasta ainda pouco conhecida no Brasil: Maya Deren. Se a memória é criada por atos de edição, segundo Wally Salomão, ou por alinhamentos da memória, segundo Chris Marker, é preciso pensar na questão de uma edição e de um alinhamento vertical. Ou seja, a cola, ou a costura, de seus fragmentos, pode se dar também através de camadas de tempo.

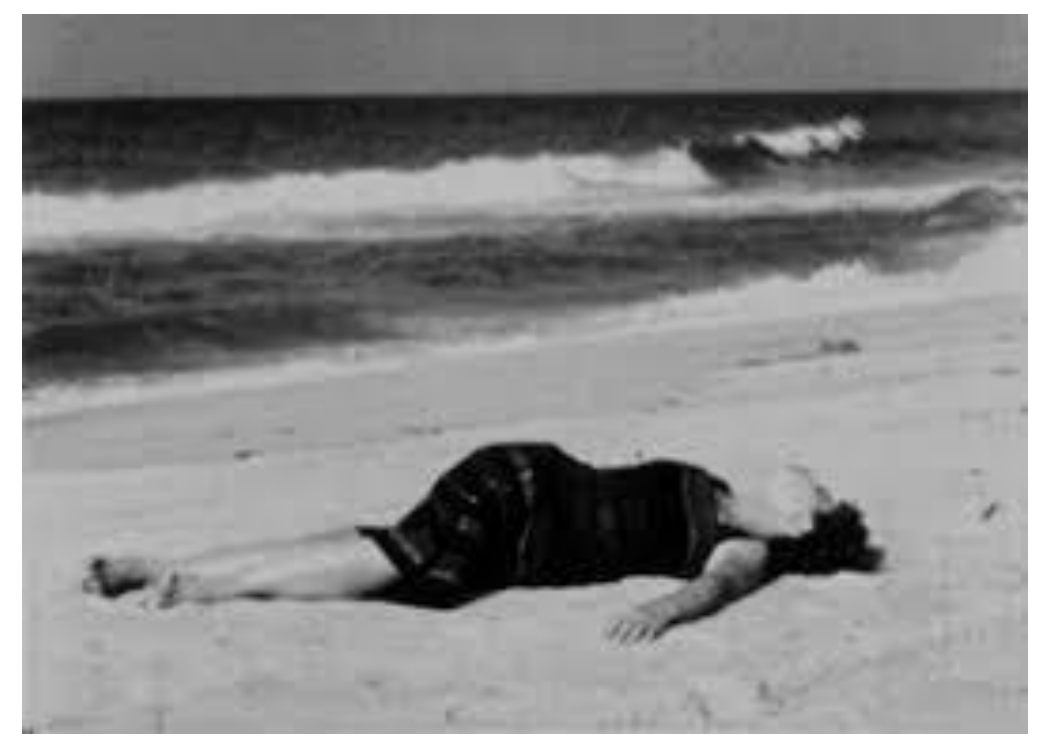

At Land, Maya Deren, 1944

No filme At Land $^{1}$ (1944), de Deren, relações entre paisagem e memória são colocadas em quase todas as sequências, uma vez que a cineasta cria, por meio de recursos de montagem, uma contínua fusão entre as paisagens reais e imaginárias. O resultado é um filme com uma paisagem elástica, que expande o espaço rumo a novos percursos. Através da compilação de camadas de tempo diversificadas, em busca da construção do que a cineasta chamou de Cinema Vertical $^{2}$, Deren cria um filme que se atualiza a cada sequência. Ou seja, um filme que está sempre a procura de novas paisagens criadas a partir de deslocamentos entre o real e o imaginário.

\footnotetext{
${ }^{1}$ Disponível em: https://www.youtube.com/watch?v=OVMV0j6XVGU Acesso em: 14/10/16.

${ }^{2}$ Em um simpósio sobre cinema e poesia realizado em 1953 em Nova York, Maya Deren defendeu sua teoria sobre o Cinema Vertical: "The distinction of poetry is its construction (what I mean by 'a poetic structure'), and the poetic construct arises from the fact, if you will, that it is a 'vertical' investigation of a situation, in that it probes the ramifications of the moment, and is concerned with its qualities and its depth, so that you have poetry concerned in a sense not with what is occuring, but with what it feels like or what it means." Disponível em: https://www.youtube.com/watch?v=HA-yzqykwcQ Acesso em: 14/10/16.
} 


\title{
4) A escrita como inscrição da memória
}

Lembrar significa ler vestígios; requer imaginação, atenção do olhar, construção.

Andreas Huyssen

Se a escrita é um rastro, um vestígio que insere o espaço no tempo, então organizar os fragmentos da memória em função de uma escrita não implicaria em editar as paisagens em que vivemos a fim de avançar rumo a novas paisagens? Ou seja, a fim de avançar rumo a novas paisagens, não seria necessário inscrever nossa memória, deixar rastros, vestígios nas paisagens pelas quais percorremos?

Para falar sobre a escrita em si, Jeanne Marie Gagnebin recorre a Aleida Assman:

\begin{abstract}
Aleida Assman se detém ainda numa outra metáfora-fundadora de nossa concepção de memória e de lembrança: a da escrita, este rastro privilegiado que os homens deixam de si mesmos, desde as estelas funerárias até os e-mails efêmeros que apagamos depois do uso sem esquecer, naturalmente, os papiros, os palimpsestos, a tábua de cera de Aristóteles, o bloco mágico de Freud, os livros e as bibliotecas: metáforas-chave das tentativas filosóficas, literárias e psicológicas de descrever os mecanismos da memória e do lembrar. Embora sempre tivesse havido uma outra imagem para dizer esses mecanismos, a imagem da imagem justamente, parece que até hoje, e apesar da tão comentada preponderância contemporânea das imagens sobre o texto, continuamos falando de escrita, escritura, inscrição quando tentamos pensar em memória e lembrança. (GAGNEBIN, 2006, p. 111)
\end{abstract}

Acerca das relações entre escrita, memória e paisagem, desenvolvemos não só a questão de um atravessamento da paisagem, como também a de um alinhamento da memória. Na arte contemporânea em geral e, particularmente, na criação audiovisual contemporânea, é possível identificar uma aproximação das paisagens através da organização de vestígios, sejam eles encontrados naturalmente nas paisagens, sejam eles produzidos especialmente para elas. Reconhecer que as paisagens tenham sido percorridas por outros que ali deixaram vestígios ou produzir artificialmente vestígios para se deixar nas paisagens é algo que permite a criação de novas paisagens e um avanço para o futuro.

Como indica a filósofa Anne Cauquelin, a noção de paisagem está relacionada tanto ao meio ambiente físico como à arte do enquadramento e da composição. Poderíamos relacionar a visão de Cauquelin acerca da paisagem com a visão do filósofo Georgio Agamben acerca da natureza. Se pensarmos na questão da natureza como pensamos na questão da nudez, seguindo Agamben, podemos pensar na paisagem como numa veste, isto é, como algo que vela a natureza. Nesse sentido, somente através da relação entre a paisagem e a não-paisagem seria possível perceber a natureza. Partindo do princípio de que a paisagem só existe em função de um enquadramento humano (não necessariamente visual), ou seja, de uma seleção, de uma escolha, de um recorte do mundo, podemos sugerir que ela funciona como um véu sobre a natureza, como uma veste sobre um corpo nu. 
Recordemos que Lucrecio já nos dizia que a natureza é para ser evitada, e nós podemos evitá-la, acrescentava ele: sim, porque temos a preciosa paisagem que, ao remeter à natureza, a domestica, interpondo entre ela e nós seu análogon civilizado. (CAUQUELIN, 2007, p. 139)

Para se avançar rumo a novas paisagens, portanto, será necessário um cruzamento entre memória e paisagem, tanto no sentido de um atravessamento espacial quanto no sentido de um alinhamento temporal. Esse cruzamento, entretanto, será sempre uma negociação entre escrita e apagamento, lembrança e esquecimento, fluxo e corte.

\section{Referências}

AGAMBEN, Giorgio. Nudez. Belo Horizonte: Autêntica Editora, 2014.

ANDRADE, Carlos Drummond de. Corpo. Rio de Janeiro: Ed. Record, 1987.

CARERI, Francesco. Walkscapes. São Paulo: Ed. G. Gili, 2013.

CAUQUElin, Anne. A Invenção da Paisagem. São Paulo: Martins Fontes Editora, 2000.

GAGNEBIN, Jeanne Marie. Lembrar, escrever, esquecer. São Paulo: Editora 34, 2014.

HUYSSEN, Andreas. Culturas do Passado-Presente. Rio de Janeiro, Contraponto, 2014.

LÉVINAS, Emmanuel. Humanismo do outro homem. Petrópolis: Editora Vozes, 2012.

PESSOA, Fernando. Obra Poética em um Volume. Rio de Janeiro: Nova Aguilar, 1986.

SALOMÃO, Wally. Poesia Total. São Paulo: Companhia das Letras, 2014.

SCHAMA, Simon. Paisagem e Memória. São Paulo: Editora Schwarcz, 1995.

TIBERGHIEN, Gilles. Dossiê: Trajetória e interesses: entrevista com Gilles A. Tiberghien. Revista-Valise, Porto Alegre, v. 2, n. 3, ano 2, julho de 2012. 